\title{
El Mercurio y la prensa obrera: Dos enfoques periodísticos para construir nación
}

\author{
Recibido: 05 de octubre de 2012 \\ Aceptado: 08 de mayo de 2013 \\ Publicado: 29 de noviembre de 2013
}

Fernando Rivas Inostroza fernando.rivas@ucv.cl

Pontificia Universidad Católica de Valparaíso (Chile)

Resumen: Los medios de comunicación ayudan a construir simbólicamente la nación, principalmente a través de su acción en el ámbito de la cultura y a través de ella en las más diversas facetas y planos del quehacer ciudadano. Los modos de hacerlo, sin embargo, varían entre unos y otros. Aquí revisamos y confrontamos lo hecho tanto por El Mercurio de Santiago en 1900, a través de su primer y canónico editorial inaugural, así como también por parte de otro editorial canónico, pero esta vez de la prensa obrera chilena, redactado por uno de los próceres del sindicalismo chileno, como fue Luis Emilio Recabarren.

El primer tipo de prensa apela indirectamente a sus lectores respecto del Chile deseado, mientras que la segunda es explícita y directa, en un estilo más bien frontal y sin lugar a interpretaciones. Se trata de dos modalidades de construir nación, que obedecen a las características de ambos medios y al estilo pertinente para sus públicos. Sin embargo, sus estilos son algo más que un simple asunto de retórica.

Palabras clave: Nación, prensa obrera, prensa sibilina, prensa objetiva, prensa pedagógica, prensa redentora, modelos de prensa, élite, obreros, discurso.

Abstract: The media helps to symbolically build the nation by its effect, mainly on culture and, through it, on the different sides and areas of the citizens' activities. However, the means vary. Here we review and compare what was done by El Mercurio de Santiago with its first and canonic editorial in 1900, to what was done by another canonical publication, this time a Chilean labor press. The latter was written by one of the dignitaries of the Chilean syndicalism, Luis Emilio Recabarren. 
The first kind of press indirectly talks to the readers about the Chile expected, whether on the second kind the message comes in an explicit and direct way, which leaves nothing to open interpretation. Our work is about two different ways to build a nation, which depend on the characteristics of both media and on the relevant style to their target public. Nevertheless, their styles are not simply a rhetoric issue.

Key words: Nation, Labor Press, Sybilline Press, Objective Press, Pedagogical Press, Redemptive Press, Journalistic Models, Elite, Labourer/worker, Speech.

\section{Introducción: Funciones de la prensa}

Es sabido que la acción de la prensa no se limita simplemente al hecho de "informar, interpretar, guiar y divertir", como aseguran algunos estudiosos del periodismo (entre ellos Fraser Bond), sino que también cumple un papel con incidencia social, a través de la continua formación y reformulación de la opinión pública.

La prensa crea opinión pública y a través de ella propicia la adopción de decisiones en los más variados ámbitos, siendo las de tipo económico y políticas aquellas más evidentes. Se trata del ancestral proceso humano que se inicia en el pensar, que se objetiva en el decir y que se concreta finalmente en la acción, a través de la decisión.

En este sentido, la prensa cumple un rol social significativo por cuanto aporta en la construcción de la sociedad, al facilitar no sólo el diálogo sino que también algunos de los insumos para la adopción de las decisiones, como por ejemplo en la elección de las autoridades, que es el caso más evidente.

Sin embargo, su acción es mucho más amplia y remite también a la formación y difusión de propuestas o modelos de sociedad que son ofertados al espacio público como convenientes de impulsar, incluyendo muchas veces un determinado orden social o la modificación del existente. Hay aquí una relación estrecha entre la prensa y el ejercicio del poder, como expresión de la hegemonía social y la constitución del poder al interior de la sociedad.

Históricamente, la prensa (al menos en Hispanoamérica) ha aportado en la construcción de las diferentes naciones, principalmente después del término del dominio español y del afianzamiento de los procesos independentistas. La prensa, al igual que en Europa, tras la invención de la imprenta, sirvió como mecanismo de expansión homogénea de las ideas y de las propuestas de transformación política, social, cultural, económica y religiosa.

En nuestro continente, la prensa, en su amplia diversidad (pues hay que tener en claro que tiene distintas y disímiles expresiones) ayudó a la conformación de los nuevos Estados-naciones o al menos aportó al debate para dicho proceso. En el caso de Chile, tal aporte se vio desde los albores de la patria con La Aurora de Chile y siguió posteriormente con una multiplicidad de publicaciones periódicas de vida efímera y algunas que lograron arraigarse y proyectarse en el tiempo como El Mercurio de Valparaíso y El Ferrocarril, por ejemplo, durante el siglo XIX. 
Sin embargo, es a finales de este siglo y a principios del siglo $\mathrm{XX}$, cuando se produce una eclosión de nuevas publicaciones, debido a las mejoras técnicas y al surgimiento de un creciente mercado de lectores, así como por el incremento de la lectura debido al desarrollo y expansión de la educación pública. En esta época, leer no era sólo un recurso para informarse, sino que también constituía un medio para aprender, para ascender socialmente, para obtener reconocimiento y adscribir a un grupo social con estatus y prestigio. Es en esta época, durante el cambio de siglo, que las publicaciones (y en especial los periódicos) logran un alcance masivo en los distintos circuitos de la cultura letrada y en los diferentes niveles sociales.

\section{Aparición de la prensa obrera}

Una muestra de esta diversidad es la aparición de la prensa obrera y la prensa satírica en los sectores populares, las cuales son críticas del sistema social y reivindicativo del rol político, social y transformador de los trabajadores.

Sin embargo, también es el momento para el surgimiento de nuevos y ambiciosos proyectos editoriales de la élite como El Mercurio de Santiago y posteriormente el Diario Ilustrado, así como una serie de publicaciones como la revista Zigzag, también de El Mercurio; la revista Sucesos y una serie de diarios regionales de igual origen mercurial.

Para apreciar esta diversidad y el modo de enfrentar la labor periodística, se han escogido dos publicaciones de la misma época (1900 y 1901) que corresponden a dos estilos muy distintos de ejercer el periodismo y de contribuir a la formación simbólica de la nación.

Se trata del editorial de la primera edición de El Mercurio de Santiago (1/VI/1900) y de un editorial del periódico La Democracia (21/IV/1901), compuesto por Luis Emilio Recabarren, el reconocido líder sindicalista, a quien se considera como el padre del movimiento obrero en Chile. El primero lleva por título: "Dos palabras a los lectores de Santiago", en tanto que el segundo se denomina "El deber de la prensa obrera".

El Mercurio (1/VI/1900) expone las razones de su aparición vespertina en Santiago:

\section{"Dos palabras a los lectores de Santiago}

Debemos explicar en unas pocas palabras cuáles son los propósitos a que ha obedecido 'El Mercurio' al ofrecerles desde hoy una edición especial al público de Santiago. La edición de Valparaíso no puede llegar a Santiago sino en el espreso de cerca de las once de la noche, hora que no es dable hacer el reparto de un diario ni encontrarse lectores.

De esta suerte la distribución del Mercurio ha tenido que efectuarse en Santiago en la mañana del día siguiente al de su salida, y a la misma hora en que ya están en circulación los diarios de la mañana con las noticias telegráficas, recibidas en la noche, después de publicado El Mercurio.

No puede pues aprovechar el público en Santiago los sacrificios que El 
Mercurio hace para proporcionar a sus lectores un servicio extraordinario de noticias telegráficas.

La edición especial que hoy se empieza a publicar en Santiago permitirá que los lectores de aquí puedan aprovechar con toda oportunidad ese servicio telegráfico.

La diferencia puede ponerse más de manifiesto con un ejemplo: Las noticias telegráficas del 31 de mayo recibidas del extranjero, del norte y sur de la República, hasta después de las 11 de la mañana de ese día no han podido ser conocidas por los lectores de Santiago sino hoy en la mañana, mientras que con la edición especial que aquí se va a tirar, se van a conocer a las 5 de la tarde del mismo día en que llegan de afuera. Así, en el presente número, se dan noticias de Europa, llegadas hasta las 3 y 1/2 PM, gracias a la diferencia de horario, pero que se refieren a noticias o hechos acontecidos hasta las 7 de la noche de Argentina hasta las 4 PM y del Norte y Sur del país, hasta la misma hora. Ya que para que el público pueda utilizar de una manera más general los sacrificios hechos para dar a 'El Mercurio' un especial servicio telegráfico, nos hemos visto en el caso de publicar una edición en Santiago; hemos querido aprovechar el aparecimiento de esta para inaugurar una colaboración ampliamente organizada y en condiciones tales que, ajena a todo espíritu de partido o sectarismo filosófico o social, tenga un verdadero carácter nacional, y pueda, mediante el concurso de ocho de nuestras más distinguidas ilustraciones, publicar -sobre literatura, ciencias sociales, jurisprudencia, bellas artes, diplomacia, higiene, ciencia militar y ciencias matemáticas y astronómicas- revistas en que estas interesantes materias sean tratadas con mayor detención y profundidad que en los artículos del día, escritos al correr de la pluma con la misma improvisada rapidez de los acontecimientos.

Por lo demás, al dirigir nuestra primera palabra al público de Santiago en esta edición dedicada especialmente a él no tenemos para qué explicarles cuáles son los propósitos a que obedece 'El Mercurio' porque aún cuando su circulación ha sido aquí sumamente inferior a la de Valparaíso no por eso han podido ser desconocidos los propósitos de su misión, que cada día se han acentuado más a medida que han ido creciendo también en importancia, junto con el país, los intereses nacionales que incesantemente llaman nuestra atención.

Conocida es ya, hasta ser tradicional, la respetuosa y tranquila actitud del Mercurio para discutir con serenidad inalterable las más graves materias del orden político, económico, administrativo o internacional, sin salir de los límites de la moderación, por más que en algunos casos tocara a rebato el fervor de la pasión patriótica o el ardimiento de la de partido.

Esa norma de conducta, que es ya una tradición para El Mercurio, no habrá de alterarse jamás; como tampoco habrá de olvidar en ningún caso que el decano de la prensa en Chile no puede afiliarse entre los elementos de agitación que propenden a exaltar las pasiones, sino entre los elementos de orden que tienen que estar siempre del lado de todo aquello que asegura la estabilidad social, política, económica y administrativa, y el cultivo de nuestras relaciones de paz y cordialidad con todas las naciones del mundo; 
sin que esto signifique que nos desentendamos del abuso, del error o de los extravíos cuando en ellos se incurra en cualquier ramo de nuestra actividad nacional, o en el ejercicio de cualquiera de nuestros poderes públicos, de cuya rectitud en el cumplimiento de sus deberes depende la estabilidad de esos mismos poderes, la de la nación y la prosperidad de todos sus intereses. No habrá tampoco de alterarse en lo más mínimo el carácter del Mercurio, que es el de una entidad moral consagrada patrióticamente a los intereses del país, sin representación personal de ningún género, de tal suerte que en la redacción de las columnas del Mercurio no aparece jamás ni la persona A ni la persona $\mathrm{B}$, sino una elevada personalidad moral, impalpable, ya para ser deprimida por los ataques, ya para ser ensalzada por los aplausos.

Las columnas de El Mercurio son arsenales donde se forjan armas que jamás pueden herir a las personas, y son a la vez almenas donde sus combatientes no pueden sentirse heridos con los proyectiles envenenados que personalmente pudieran dirigirles del campo contrario.

El diario, decía Ambrosio Montt, es una voz que sale de las entrañas de la sociedad, como el trueno y el relámpago salen, resuenan y alumbran desde el seno de la atmósfera.

En efecto no hay para que averiguar quien es el que habla cada vez que se oye esa voz; porque lo importante no es saber qué persona emite las ideas, sino qué valor tienen en sí mismas, hasta qué punto interpretan con fidelidad los verdaderos intereses del país y están inspiradas en la justicia, la verdad y el derecho.

No hay tampoco para qué averiguar si quien emite esas ideas es rico o pobre, nervioso o flemático, creyente o libre pensador, reaccionario, conservador o reformista

Nada importa que adolezca de tales o cuales defectos, si sus ideas son buenas; o que esté adornado de brillantes cualidades personales, si sus ideas son malas o desacertadas.

Hay pues que combatir o aceptar las ideas no en relación a la persona que las emite sino a la propia bondad o malas cualidades intrínsecas de esas mismas ideas. Hay quienes llegan a prescindir de las personas que emiten las ideas, esto es del personal de redacción, pero creen que a todo diario debe exigírsele que esté afiliado con algunos de los partidos en lucha y si no lo está piensan que no debe contar con él la opinión pública, como si la vida nacional estuviese reducida únicamente a la apasionada polémica de los intereses de partido y el espíritu de estos debiera predominar en todo.

El Times -dice a este propósito un distinguido escritor- es la reproducción viva de la opinión del pueblo inglés. No es tory ni es whig, ni es conservador ni es liberal, ni es high church ni low church, ni retrógrado, ni radical, ni aristócrata, ni plebeyo. Es todo eso y más que eso; es inglés. El Times no ofrece incienso a ningún hombre a ningún partido; ora los eleva, ora los abate, según lo requiera la gloria y el bienestar de la nación.

Y todavía agrega el mismo autor: 
El Times es el varón justo de Horacio: altivo, desdeñoso del tirano que lo amenaza y de la muchedumbre que lo ultraja, incorruptible por orgullo, justo por elevación de alma. Ni recibe honores del poderoso, ni acepta el oro del rico, ni lo doblegan los golpes del violento, ni lo seducen las artimañas del hábil.

A esto es a lo que debe tender nuestra prensa: a que cada diario sea una entidad moral en la cual no aparezcan ni para el bien ni el mal, ni para las odiosidades ni los aplausos, las personas que componen su redacción, sino que desaparecen absorbidas en la grande y elevada entidad moral del diario, incapaz de atacar otra cosa que el mal, el error, el abuso, considerados en sí mismos y sin atender de qué personas proceden; incapaz también de amar otra cosa que la justicia, la verdad y el derecho; incapaz de censurar por antipatías, por hacer daño o causar molestia, ni de aplaudir o tributar honores sólo por lisonja, exagerada solicitud o adhesión fanática.

Cuando nuestra prensa llegue, en general, a esta altura, se hará sumamente poderosa; porque no hay nada que haga más temibles sus ataques que la moderación ni nada que haga más valiosos sus aplausos que la parsimonia para tributarlos sólo a quienes estrictamente los merecen".

A continuación, se reproduce el editorial de Luis Emilio Recabarren, titulado "El deber de la prensa obrera", publicado en el diario La Democracia (21/IV/1901):

\section{"El deber de la prensa obrera}

La prensa obrera tiene por misión sagrada contribuir a la ilustración y difundir la cultura en las costumbres de los pueblos.

Un periódico que llegue a las manos de un hijo del trabajo debe ser un libro en el cual encuentre la savia vivificante para fortalecer el espíritu cuando, abatido por las luchas de la vida, se siente adormecer.

Debe llevar en sus caracteres palabras de enseñanza y de ejemplo, en estilo claro y correcto que revele la buena intención de la pluma que los traza.

Debe rebatir las ideas del adversario o del amigo cuando no las crea buenas, con cultura, moderación y altura de miras, procurando convencer al que crea que marcha extraviado con buenas razones y con argumentos que se basen en la lógica y en un criterio sano y despejado.

Sí se combaten las ideas del amigo, por creerlas no muy buenas, es necesario procurar convencerlo que va por camino malo y señalar la recta por donde debe seguir.

Pero si ideas lanzadas con buenos propósitos y con la conciencia de su bondad son atacadas con insultos que denotan poca cultura y con prejuicios de suyo ligeros e injuriosos que arrastran y rebajan a la pluma que los produce para herir a personas que no usan el lenguaje mordaz y atrevido para atacar o combatir, no se conseguirá convencer los errores, porque no es esa la forma que se debe emplear por hombres que con buenos propósitos trabajan por ilustrar a los que saben menos.

Podemos errar en nuestras apreciaciones doctrinarias, porque no tenemos 
la pretensión de ser infalibles, cuando estudiamos cuál será el mejor medio para llegar más luego a la realización de ideales que hemos abrazado con fe y entusiasmo y estamos dispuestos a aceptar en nuestras propias columnas las polémicas y el que se señale que nuestras ideas no son las mejores, cuando estas sean tratadas dentro del terreno en que es natural que lo hagan los demócratas que aman generosamente a su causa: con elevación de criterios, sin herir susceptibilidades, sin hacer suposiciones mal intencionadas que recuerden aquel adagio que dice 'el ladrón cree que todos son de su condición', y que inspiran a contestar, cuando estos no quedan muy debajo de la moralidad, al nivel de la bajeza.

Los periódicos obreros que se estilen en esa forma merecerán siempre el honor de las atenciones, la consideración de los adversarios, las simpatías de los lectores e ilustrarán a los que necesiten de la enseñanza y contribuirán a hacer desaparecer los malos hábitos.

Pero aquéllos que se aparten de este terreno ni ilustran ni convencen. Más bien, distancian en vez de aproximar.

Estas líneas han sido trazadas por la indignación que me ha producido la lectura de una correspondencia en un periódico obrero destinado a ilustrar, no a ofender, con la intención de llamarlo al buen juicio".

Ambos editoriales pueden ser considerados como canónicos en el sentido de que contienen los elementos centrales y constitutivos de su forma de concebir el ejercicio del periodismo, la construcción de mundos que propician, la utopia que promueven, así como algunos de los criterios técnicos de cobertura, el estilo de redacción y los recursos que deben emplear para lograr una mejor comunicación con los lectores.

Uno aborda lo que debe ser el deber de la prensa obrera, con el fin de precisar cuál es el sentido y la obligación de la prensa dirigida a los trabajadores y representativa de los mismos. En tanto, el otro editorial expresa que sólo pretende hacer un alcance a los lectores de Santiago, mediante la enunciación de dos palabras, que no desean distraer la acción de informarse que desarrollan los lectores.

Además, con eso también relativiza la importancia y trascendencia del artículo, por cuanto parece no comportar la importancia que ahora le podemos asignar, ya que, de algún modo, se trata de un contenido conocido toda vez que los lectores ya sabían del carácter, intenciones, costumbres y usos de El Mercurio por su versión en Valparaíso. De manera que asume el carácter de ser sólo una declaración necesaria para un número inaugural, para el inicio de una nueva etapa, pero que no implica un cambio sustancial de lo ya conocido.

\section{Análisis del discurso}

Ambos textos fueron confrontados mediante el análisis de discurso, según categorías que son propias de cualquier empresa, entre ellas las periodísticas, como la misión y visión de la misma, en el sentido de los objetivos que se proponen y los medios de que disponen para 
lograrlos. Asimismo, se establecieron categorías de acuerdo con el proceso de comunicación que desarrollan, mediante las definiciones que realizan del emisor, del mensaje, del canal, del contexto y del receptor.

Si ambos textos son declarativos y evidencian la elevada significación moral y pedagógica que representan, uno (el obrero) hace su exposición en forma directa y asumiendo la noción de deber, como obligación ética y moral con la ilustración de los trabajadores. Sin embargo, el otro expone su postura en forma velada, a través de sólo dos palabras a los lectores de Santiago, que hablan más bien del estilo subrepticio, sibilino, y de lectura entre líneas que ha caracterizado a dicho diario a lo largo de su trayectoria. Allí se entregan, aparentemente, sólo los datos y la interpretación la debe hacer el lector.

Se trata de dos tipos de retórica periodística: por un lado encontramos en el texto de Recabarren una expresión directa, simple y evidente por sí misma, cuyo fin es persuadir a los lectores, mediante una exposición razonada y argumentativa, mientras que la otra se inscribe dentro del modelo anglosajón de la objetividad, en el cual el discurso sólo entrega antecedentes y datos, sin emitir opiniones, aún cuando estas van de modo implícito y velado. ¿Cuál de las dos tendrá mayores efectos?, ¿Se puede extraer de la comparación una sugerencia editorial, en cuanto a qué estilo ocupar para persuadir?

En cuanto a la misión que tienen ambas empresas, en su calidad de emprendimientos periodísticos, la prensa obrera asume para sí misma una "misión sagrada", un deber que la posiciona en el ámbito de lo supremo, del deber redentor divino, en cuanto al mejoramiento de la humanidad... Ella dice: La prensa obrera tiene por "misión sagrada", contribuir a la ilustración y difundir la cultura en las costumbres de los pueblos.

Esa misión tiene por finalidad la superación de aquellos que socialmente tienen menos o están más desfavorecidos y busca la superación de su condición a través de su educación, formación y acrecentamiento de su cultura, el cual además es identificado con el pueblo, con los sectores populares de la nación. En este sentido, la prensa obrera está ayudando a mejorar las condiciones humanas del sector más numeroso de la población y, por lo tanto, está haciendo una contribución a la formación y fortalecimiento del capital cultural de la nación.

El Mercurio, si bien se define también como una institución moral de elevada estatura, vincula su acción editorial, su misión, con el hecho de informar y dar cuenta de los temas que son de interés nacional, respecto de los cuales manifiesta una preocupación permanente e incesante. El Mercurio no adscribe editorialmente a un sector social. Por el contrario, su alocución es indefinida e imprecisa; sin embargo, por su estilo, por el lenguaje, por los conceptos ocupados, y las referencias que hace a la prensa extranjera, evidencia que sus destinatarios son, en general, personas educadas, personas capaces de decodificar y de entender los contenidos. Es decir, da por sentado que quienes leen sus páginas son personas con cultura, a las cuales se pretende entregar en forma de colaboración amplia y organizada un servicio informativo que acreciente su vinculación con la realidad nacional e internacional. 
$\mathrm{Su}$ función está pensada principalmente sobre los intereses nacionales y de las preocupaciones propias del país, respecto de las cuales declara no sólo su interés, sino que las convierte en el objeto de la acción periodística. En otras palabras, El Mercurio hace una declaración en función del conjunto de Chile, respecto del cual ofrece una cobertura extensa y profunda, caracterizada sin embargo, según dice, por ser ajena a todo espíritu de partido o sectarismo filosófico y social, con un sentido que se declara inclusivo, al contar con un verdadero "carácter nacional".

Esa declaración respecto de permanecer distante de los espíritus de partido o ajeno al sectarismo filosófico y social no es más que una declaración de intenciones, pues se ha visto cómo el periódico se abanderiza con la élite nacional y rechaza, objeta y descalifica, las opciones políticas sociales o que implican una transformación radical de la sociedad en la búsqueda de una mayor igualdad. Sin embargo, en su apelación a cierta actitud imparcial y prescindente, pretende fortalecer una posición declarativa de la verdad, del juicio justo, exacto e irrebatible.

El Mercurio se erige a sí mismo como el detentor de la verdad; el representante del "Juez Supremo", capaz de dar a conocer la versión cierta de los hechos, cuando en verdad sólo ofrece la versión que se acomoda más a sus intereses y a su opción utópica. Este juego, sin embargo, es el que se proyecta durante el siglo XX y alcanzó un elevado grado de credibilidad hasta décadas muy recientes.

En cuanto a la visión de ambos tipos de prensa (es decir, la modalidad y los recursos que declaran emplear para llevar adelante su visión) la prensa obrera se autoconcibe como "un libro en el cual encuentre la savia vivificante para fortalecer el espíritu". El afán de trascender, como si fuera un libro, evidencia el interés por aparecer como un instrumento significativo, profundo y valioso, con una validación social amplia y que sirve para aportar energía y entusiasmo al obrero "cuando abatido por las luchas de la vida, se siente adormecer". Es decir, la prensa obrera pretende convertirse en un instrumento útil que insufle valor y energía a los obreros para que no cejen en su empeño de transformar el mundo y lograr mejores condiciones de vida.

El Mercurio, en tanto, para llevar adelante su tarea informativa "nacional", declara ser partidario y promotor del orden social, a través de una actitud reposada, serena y moderada, alejada de las pasiones:

"Conocida es ya, hasta ser tradicional, la respetuosa y tranquila actitud del Mercurio para discutir con serenidad inalterable las más graves materias del orden político, económico, administrativo o internacional, sin salir de los límites de la moderación, por más que en algunos casos tocara a rebato el fervor de la pasión patriótica o el ardimiento de la de partido".

El Mercurio se compromete con la mantención del orden social y aboga por un debate sereno acerca de la realidad nacional en sus más distintos aspectos. La mantención 
del orden social implica que quienes están en los puestos de poder o en una situación privilegiada van a permanecer allí y que quienes no lo están van a seguir en sus sitios. Hay aquí una suerte de disciplinamiento simbólico, que tiende a conservar y proyectar la mantención de las estructuras sociales y la división de la sociedad en clases inalterables y de una composición permanentemente igual, sin modificaciones.

Mientras la prensa obrera confía en el poder transformador de la educación, El Mercurio pretende justificar el statu quo mediante un debate razonado y parsimonioso, que no atente contra la estructuración tradicional de la sociedad:

“...el decano de la prensa en Chile no puede afiliarse entre los elementos de agitación que propenden a exaltar las pasiones, sino entre los elementos de orden que tienen que estar siempre del lado de todo aquello que asegura la estabilidad social, política, económica y administrativa, y el cultivo de nuestras relaciones de paz y cordialidad con todas las naciones del mundo".

En cuanto al destinatario de ambos tipos de prensa, la percepción que ofrecen del mismo es muy diferente en uno y otro caso. El editorial de la prensa obrera se refiere a ellos como "un hijo del trabajo", “(d)el adversario" o "(d)el amigo" y "los lectores", lo que los identifica como sujetos simples, que se ganan la vida trabajando y que pueden estar a favor o en contra de sus postulados.

En cambio, el destinatario de El Mercurio aparece asimilado al destinatario del periódico inglés The Times. Para eso reseña sus propias cualidades que en definitiva son las que también describen a sus lectores. Al respecto dice que "no es tory ni es whig, ni es conservador ni es liberal, ni es high church ni low church, ni retrógrado, ni radical, ni aristócrata, ni plebeyo", sino que es todo eso y más que eso; en definitiva que es inglés. En el caso de El Mercurio, siguiendo la analogía, su destinatario es el chileno, que tampoco es conservador ni liberal, ni de clase alta o de clase baja, ni retrógado, ni radical, ni aristócrata o plebeyo, sino que está por sobre todas esas distinciones.

El modo de elaborar el mensaje también difiere en ambos casos. Mientras la prensa obrera se distingue por "llevar en sus caracteres palabras de enseñanza y de ejemplo, en estilo claro y correcto que revele la buena intención de la pluma que los traza", El Mercurio señala que lo importante no es saber qué persona emite las ideas, sino qué valor tienen estas en sí mismas y hasta qué punto interpretan con fidelidad los "verdaderos" intereses del país y si están inspiradas en la justicia, la verdad y el derecho. El Mercurio enfatiza que no importa la identidad de sus redactores, sino que la calidad de sus ideas e informaciones, de modo que ellos se subsumen perdiendo sus nombres en la elevada entidad moral del diario.

El mensaje de la prensa obrera, en tanto, tiene como finalidad "rebatir, las ideas del adversario o del amigo, cuando no las crea buenas, con cultura, moderación y altura de miras, procurando convencer al que crea que marcha extraviado con buenas razones y 
con argumentos que se basen en la lógica y en un criterio sano y despejado". Esta es una actitud pedagógica, de una prensa pedagógica, basada en la fuerza de la razón y en el convencimiento de que la cultura y las buenas maneras dan como fruto acciones adecuadas, pertinentes y justas.

El Mercurio, en cambio, insiste en que hay "que combatir o aceptar las ideas no en relación a la persona que las emite sino a la propia bondad o malas cualidades intrínsecas de esas mismas ideas". Obviamente, quien califica esas ideas es el propio diario.

Acerca del contexto en que se dan estos mensajes, la prensa obrera estima que aquellos periódicos obreros que se estilen ("con elevación de criterios, sin herir susceptibilidades, sin hacer suposiciones mal intencionadas") merecerán siempre el honor de las atenciones, la consideración de los adversarios, las simpatías de los lectores e ilustrarán a los que necesiten de la enseñanza y contribuirán a hacer desaparecer los malos hábitos.

Luis Emilio Recabarren aboga aquí por una actitud bien intencionada por parte de los periódicos obreros, alejada de los ataques virulentos y de la maledicencia que él ha podido observar en algunos de ellos y que es lo que lo mueve a redactar el editorial. A su juicio, la prensa obrera con una actitud correcta y criteriosa puede revertir las consideraciones negativas y ganarse el concurso de los adversarios y las simpatías de los lectores.

En cambio, El Mercurio siguiendo su modo tradicional de ejercer el periodismo y teniendo como norte un actuar semejante al de The Times, hará que la prensa se haga sumamente poderosa, porque "no hay nada que haga más temibles sus ataques que la moderación ni nada que haga más valiosos sus aplausos que la parsimonia para tributarlos sólo a quienes estrictamente los merecen".

En este sentido, ambos medios parecen coincidir en algunos aspectos, como el de la moderación y la tranquilidad para dirigirse a sus lectores. Uno está destinado a los trabajadores, que en ocasiones por su desmedrada cultura pueden caer en el insulto o la descalificación, mientras que el otro valora también la ponderación y la mesura, como medios para lograr la asimilación de sus ideas por parte de sus lectores. El primero está dedicado a convencer, sin embargo, el segundo busca entregar su venia a quien considera correcto y digno merecedor de sus elogios. La prensa obrera busca educar a sus lectores, mientras que El Mercurio se erige como una autoridad que pretende distinguir y destacar a aquellos actores sociales que estime relevantes.

En cuanto al canal por el cual emiten sus informaciones, la prensa obrera declara que lo hace a través de los propios periódicos obreros. En cuanto, a El Mercurio también sus ejemplares son el nexo con sus lectores. Sin embargo, en cuanto a sus vías de información, este también declara una dependencia y uso permanente del servicio telegráfico, con el fin de entregar la mayor cantidad de informaciones nacionales e internacionales, mediante un sistema informativo tecnificado, rápido y continuo. 


\section{Reflexiones finales}

En conclusión, podemos ver a través de estos dos editoriales, dos modos distintos de concebir el periodismo, aún cuando ellos se topan en el afán pedagógico que mantienen respecto de sus lectores y en la tranquilidad con que conciben su función difusora. Sin embargo, uno (el de la prensa obrera) confía principalmente en la argumentación y en la razón explícita, como medio de persuasión para la conquista de nuevas condiciones de vida de los trabajadores; mientras que el otro (El Mercurio) se erige como una elevada autoridad llamada a calificar y determinar aquellos elementos y personas que merecen ser destacadas socialmente, en aras de lo que él determina que son los intereses nacionales, mediante una retórica indirecta, que apela a la "objetividad" y con eso a una formulación de la verdad.

De esta manera, la prensa obrera formula un periodismo de alcance masivo y con una retórica sencilla y lógicamente argumentada, cuyo fin apunta también a la transformación de la sociedad. El Mercurio, en tanto, busca influir con su discurso en los distintos sectores sociales, de modo que estos acojan sus planteamientos y puedan hacer efectiva su visión de Chile.

En este sentido, los modelos discursivos de ambos son disímiles: transcurren por carriles comunicativos diferentes, que incluso pueden ser paralelos o complementarios, según la lectura que se haga de los mismos y el modo que se emplee para leerlos. Ciertamente, ambos tienen como finalidad construir nación, pero el modo de hacerlo difiere no sólo en la retórica, sino que también en el contenido y el tipo particular de contenidos que los artículos abordan.

Ambos tipos de prensa, sin embargo, coinciden en un cierto rol educativo que pretenden desarrollar respecto de sus lectores: uno al nivel del pueblo llano y sencillo, y otro desde el pedestal que le brinda su vinculación con las personas educadas, que corresponden a la élite y los sectores medios emergentes, habituado al consumo de temas nacionales y sobre todo internacionales.

De este modo, el afán pedagógico-social de ambos discursos queda en evidencia y es posible apreciar de qué modo y a través de qué recursos pretenden hacer efectiva sus particulares concepciones de mundo. De allí que cada uno propicia la conformación de una nación, acorde con sus intereses y a modos particulares de comunicación, cuando no de persuasión.

\section{Fuentes consultadas}

Arias Escobedo, O. (2009). La prensa obrera en Chile 1900-1930. Santiago de Chile: Ariadna.

Baeza, M.

(2008). Mundo real, mundo imaginario social. Teoría y práctica de sociología profunda. Santiago de Chile: Editorial Ril. 
_(2003). Imaginarios sociales. Apuntes para la discusión teórica y metodológica. Concepción: Editorial Universidad de Concepción.

Bernedo Pinto, P. y Arriagada Cardini, E. (2002). "Los inicios de El Mercurio de Santiago en el epistolario de Agustín Edwards Mac Clure (1899-1905)”. Revista Historia PUC, vol. 35, pp. 13-33.

Bhabha, H. (2000). "Narrando la nación”. En Fernández Bravo, A. (comp.). La invención de la nación. Lecturas de la identidad de Herder a Homi Bhabha. Buenos Aires: Manantial. Correa, S. (2005). Con las riendas del poder. La Derecha chilena en el siglo XX. Santiago de Chile: Editorial Sudamericana.

Darton, R. (1996). "El lector como misterio". Revista Fractal, núm. 3, año 1, volumen 1, pp. 39-63. Extraída el 11/VIII/2013 desde http:/www.fractal.com.mx/F3darton.html

El Mercurio, diario (2007). Chile en un mundo que cambia. El Mercurio 1911-1920. Santiago de Chile: El Mercurio Aguilar.

Fontcuberta, M. y Borrat, H. (2006). Periódicos: sistemas complejos, narradores en interacción. Buenos Aires: La Crujía.

Hobsbawm, E.

_(2004). Naciones y nacionalismo desde 1780. Barcelona: Crítica.

_(1998). La era del Imperio 1875-1914. Buenos Aires: Crítica.

Mattelart, A. y Mattelart, M. (2000). Pensar sobre los medios. Comunicación y crítica social. Santiago de Chile: LOM.

Ossandón, C. (1998). "El crepúsculo de los sabios y la irrupción de los publicistas". Santiago de Chile: LOM Ediciones.

Ossandón, C. y Santa Cruz, E.

_(2005). El estallido de las formas. Chile en los albores de la “cultura de masas”. Santiago de Chile: LOM Ediciones.

_(2001). Entre las alas y el plomo. La gestación de la prensa moderna en Chile. Santiago de Chile: LOM Ediciones.

Raiter, A. (2006). La caja de Pandora. La representación del mundo en los medios. Buenos Aires: La Crujía.

Recabarren, L. (1986). Recabarren. Escritos de Prensa 1898-1924. 4 Tomos. Recopiladores Eduardo Devés Valdés y Ximena Cruzat Amunátegui. Santiago de Chile: Nuestra América, Terra Nova.

Salazar, G. (2009). Mercaderes, empresarios y capitalistas (Chile, siglo XIX). Santiago de Chile: Sudamericana. 
Silva Castro, R.

_(1960). El Mercurio de Santiago (1900-1960). Santiago de Chile: Editorial Lord Cochrane. _(1958). Prensa y periodismo en Chile (1812-1956). Santiago de Chile: Ediciones de la Universidad de Chile.

Van Dijk, T.

_(2006). Ideología. Un enfoque multidisciplinario. Sevilla: Gedisa.

_(2000). El discurso como estructura y proceso. Barcelona: Gedisa.

_(1995). Estructuras y funciones del discurso. Madrid: Siglo XXI Editores. 